\section{(6) OPEN ACCESS}

\title{
Angioplasty and stenting of intracranial atherosclerosis with the Wingspan system: 1-year clinical and radiological outcome in a single Asian center
}

\author{
Simon Chun Ho Yu, ${ }^{1}$ Thomas Wai Hong Leung, ${ }^{2}$ Kwok Tung Lee, \\ Lawrence Ka Sing Wong ${ }^{2}$
}

'Department of Imaging and Interventional Radiology, Prince of Wales Hospital The Chinese University of Hong Kong, Hong Kong, China ${ }^{2}$ Department of Medicine and Therapeutics, Prince of Wales Hospital, The Chinese University of Hong Kong, Hong Kong, China

\section{Correspondence to}

Professor Simon Chun Ho Yu, Department of Imaging and Interventional Radiology, Prince of Wales Hospital, The Chinese University of Hong Kong, 30-32 Ngan Shing Street, Shatin, The New Territories, Hong Kong 852, China;

simonyu@cuhk.edu.hk

Received 27 November 2012 Revised 13 February 2013 Accepted 25 February 2013 Published Online First 19 March 2013

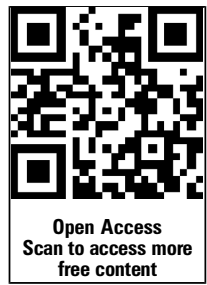

To cite: $\mathrm{Yu} \mathrm{SCH}_{\text {, }}$ Leung TWH, Lee KT, et al. $J$ Neurolntervent Surg 2014;6:96-102.

\begin{abstract}
Background This study aimed to evaluate the 1-year clinical and angiographic outcome of angioplasty and stenting of intracranial atherosclerosis using Wingspan and Gateway system.

Methods In this prospective study, patients with symptomatic lesions were treated and followed clinically and angiographically by digital subtraction angiography (DSA) for 1 year. The two primary endpoints were recurrent ipsilateral ischemic stroke and in-stent restenosis (ISR) at 1 year. Secondary endpoints included periprocedural death or stroke and all strokes at 1 year. Potential factors correlated with ISR were studied using univariate and multivariate analysis.
\end{abstract}

Results Treatment was attempted in 65 patients and successfully completed in 61 (93.8\%). Fifty-nine patients (44 men, 15 women) aged $62.86 \pm 11.38$ years with 66 stenoses (average degree of stenosis $71.78 \pm 11.23 \%$ ) underwent clinical and DSA follow-up at 1 year. There were 66 stenotic lesions. ISR occurred in 11 of the 66 lesions $(16.7 \%)$. Luminal gain occurred in 32 of the lesions (48.5\%), an unchanged lumen in $4(6 \%)$ and luminal loss in $30(45.4 \%)$. The periprocedural stroke or death rate was $6.1 \%(4 / 65)$, including three hemorrhagic and one ischemic stroke, all of which occurred at the corresponding site and resulted in death. There were no interval strokes between the periprocedural time and the 1-year follow-up. The occurrence of ISR was correlated with the degree of stenosis before treatment and was not correlated with patient age or sex, vessel diameter, location of stenosis or failure to control risk factors for atherosclerosis. Conclusions One-year clinical and angiographic outcomes of angioplasty and stenting are promising for symptomatic intracranial atherosclerosis.

\section{INTRODUCTION}

Intracranial atherosclerotic stenoses account for $8-10 \%$ of cases of ischemic stroke in the USA ${ }^{12}$ and 33\% in Asia. ${ }^{3}$ The Wingspan Stent System (Stryker Neurovascular, Michigan, USA) is currently the best known device for this indication in the English literature. ${ }^{4-6}$ Although the value of stenting with the Wingspan system has been questioned since the publication of the first Stenting and Aggressive Medical Management for Preventing Recurrent Stroke (SAMMPRIS) randomized controlled trial which indicated that aggressive medical management was superior to stenting in preventing recurrent stroke, ${ }^{7}$ it is too early to conclude that we should give up stenting because the long-term results of SAMMPRIS are still awaited. Since the primary purpose of intracranial stenting is to widen the lumen and to maintain the widened lumen of the stenotic vessels in order to prevent recurrent ipsilateral ischemic stroke, treatment outcomes in terms of recurrent ischemic stroke and in-stent restenosis (ISR) are the primary concerns. Published outcomes of the Wingspan system in the literature are essentially limited to those from the Western world, ${ }^{4-7}$ and angiographic outcomes are typically short term and incomplete with a range starting from 2 to 3 months. ${ }^{8-10}$ This study aimed to evaluate the 1-year clinical and angiographic outcome of stenting using the Wingspan system in a single center in Asia.

\section{METHODS}

\section{Study design}

This prospective single-center single-arm study was approved by the institutional review board and written informed consent was obtained. The inclusion criteria for angioplasty and stenting were: (1) patients with symptomatic ischemic stroke or a transient ischemic attack (TIA) due to intracranial stenosis $\geq 70 \%$; or (2) patients with intracranial stenosis $\geq 50 \%$ and recurrent ischemic stroke or TIA despite medical treatment with oral aspirin or clopidogrel; (3) patients with minor ischemic stroke (National Institutes of Health Stroke Scale (NIHSS) score $\leq 8$ and baseline modified Rankin Scale $\leq 3$ ); (4) location of intracranial stenosis corresponding to the vascular territory of the ischemic event; (5) diameter of vessel immediately adjacent to stenosis $\geq 2 \mathrm{~mm}$; and (6) length of each stenosis $\leq 14 \mathrm{~mm}$. There was no limit on the time between the last symptomatic event and the stent procedure. Exclusion criteria were: (1) non-atherosclerosis stroke etiology; (2) a sizeable cerebral infarct (more than one-third middle cerebral artery territory) at risk of hemorrhagic conversion; (3) contraindication to antiplatelet therapy; (4) intolerance to statin therapy; and (5) concurrent intracranial pathology.

The two primary endpoints were ipsilateral ischemic stroke or TIA more than 30 days up to 1 year after the procedure and the status of the stented segment on digital subtraction angiography (DSA) at 1 year in terms of the change in luminal diameter and the rate of ISR. Secondary endpoints included periprocedural death or stroke within 30 days and all stroke in 1 year. Cerebral DSA was 
performed for all available patients at 1 year to assess the vascular condition. Clinical visits were scheduled at 30 days, 3 months, 6 months and 12 months for blood tests, drug compliance, blood pressure recording and neurological assessment. Neurological assessment was performed with NIHSS by certified NIHSS examiners. The endpoints of stroke were evaluated according to clinical signs and symptoms as well as imaging evidence on CT or MRI. The status of control of risk factors for atherosclerosis was studied and correlated with ISR.

\section{Treatment protocol}

Two types of biplane angiographic equipment were used, Integris BV5000 for the first 59 patients and Allura Xper FD 20/20 for the rest (Philips Medical Systems, The Netherlands). All the procedures were performed by an interventional neuroradiologist with 8 years of experience in endovascular neurointervention (SCHY) and an interventional neurologist with 1 year of experience (TWHL) at the onset of the study. Procedures were performed under local anesthesia using 2\% lidocaine without patient sedation. Prestenting assessment of vascular morphology and measurements were performed with 3 dimensional rotational angiography (3DRA). Predilation of the stenotic lesion was performed once with an undersized angioplasty balloon (Gateway; Stryker Neurovascular) $<80 \%$ of the native vessel diameter. ${ }^{4-6}$ Angioplasty time from inflation to deflation was within $10 \mathrm{~s}$ and inflation pressure was 6 Atmos. Selection of the stent size was based on oversizing the native diameter of the target vessel by $0.5-1.0 \mathrm{~mm}$ and an extended stent length by $3 \mathrm{~mm}$ on either side of the lesion, ${ }^{4}{ }^{11}$ The whole stenotic lesion was covered with Wingspan stents.

All patients were treated with daily oral aspirin $100 \mathrm{mg}$ and clopidogrel $75 \mathrm{mg}$ for at least 3 days before stenting. During the procedure, unfractionated heparin was administered intravenously as a 2500 IU bolus to achieve an activated coagulation time of $180-250 \mathrm{~s}$. After the procedure, oral daily aspirin $100 \mathrm{mg}$ and clopidogrel $75 \mathrm{mg}$ were prescribed for 3 months, and daily aspirin was continued life-long. Reactivity for aspirin or clopidogrel was not tested.

\section{Methodology of stenosis assessment}

DSA data obtained immediately before and after the procedure and at 1 year after the procedure were used for analysis. The minimal luminal diameter of the stenotic lesion was measured. The DSA findings at 1 year were quantified using two different methods: (1) change in luminal diameter of the stented segment at 1 year compared with the luminal diameter immediately after stenting as baseline: degree of luminal change $=($ luminal diameter immediately after stenting-luminal diameter at 1 year)/ luminal diameter immediately after stenting $\times 100 \%$; (2) stenosis of the stented segment at 1 year compared with the diameter of the parent artery before stenting: the degree of stenosis was determined in the same way as that used in the WarfarinAspirin Symptomatic Intracranial Disease (WASID) trial, ${ }^{12-14}$ ISR at 1 year was diagnosed when the degree of stenosis was $>50 \%$ compared with prestenting baseline at a site within the stent or within $5 \mathrm{~mm}$ immediately adjacent to the stent and the degree of stenosis was $>20 \%$ of absolute luminal loss since stenting. ${ }^{8}$ The measurements were made by KTL and then adjudicated by SCHY.

Lesions showing ISR at 1 year were characterized using a modified Mehran system ${ }^{9}{ }^{15}$ (Class I: focal group, lesions involving less than half the length of the stented segment and either involving the end of the stent (IA), the body (IB) or multiple foci (IC); Class II: diffuse intrastent group, lesions involving more than half of the length of the stented segment but contained within the confines of the stented segment; Class III: proliferative group, lesions involving more than half the length of the stented segment, extending beyond the confines of the stented segment; Class IV: complete stent occlusion group).

\section{Control of risk factors for atherosclerosis}

Patients with hypertension were treated with an ACE inhibitor and a calcium channel blocker ${ }^{16}{ }^{17}$ and those with hyperglycemia were treated with metformin, sulfonylureas and/or insulin for glycemic control if diet alone was insufficient. ${ }^{18}$ All patients were treated with simvastatin, ${ }^{19}$ atorvastatin ${ }^{20}$ or rosuvastatin. ${ }^{21}$ Education by dietitians and stroke nurses on smoking cessation, diet and lifestyle modifications was provided to all patients. The targets for risk factor control were: (1) systolic blood pressure $\leq 140 \mathrm{~mm} \mathrm{Hg},{ }^{16}$ (2) glycosylated hemoglobin HbA1c $\leq 6.5 \%,{ }^{18}$ (3) low-density lipoprotein level $\leq 70 \mathrm{mg} / \mathrm{dl},{ }^{22}$ and (4) abstinence from smoking. Clinical visits were scheduled at 30 days, 3 months, 6 months and 12 months for blood tests, drug compliance and blood pressure recording. When the mean blood test results or blood pressure readings from the four clinical visits met the respective targets of risk factor control, it was considered as evidence of successful control for that risk factor. The status of control of risk factors was analyzed on a lesion basis and not a patient basis to facilitate correlation with ISR.

\section{Statistical analysis}

Univariate analysis was performed for potential correlation between ISR and factors such as patient age, sex, vessel diameter, degree of stenosis before treatment and failure of control of risk factors for atherosclerosis using the $\chi^{2}$ test for categorical variables and the Mann-Whitney test for continuous variables. Multivariate analysis for all these factors was performed using logistic regression. Correlation of the location of stenosis and ISR was analyzed with OR.

\section{RESULTS}

\section{Baseline characteristics and treatment}

Between August 2006 and August 2009, 2162 Hong Kong Chinese patients with symptomatic ischemic stroke or TIA were screened. Sixty-five fulfilled all the criteria and underwent the procedure, which was successfully completed in 61 patients (93.8\%). Clinical and DSA data at 1 year for 59 patients $(90.8 \%)$ and 66 treated lesions were available for analysis. Symptom to treatment interval was $\leq 30$ days in 33 of the 59 patients $(55.9 \%)$. There were 44 men and 15 women of mean age $62.86 \pm 11.38$ years. In the 66 treated lesions, the average diameter of the parent artery and degree of baseline stenosis were $2.97 \pm 0.62 \mathrm{~mm}$ and $71.78 \pm 11.23 \%$ (median $72.4 \%, 95 \%$ CI $49.8 \%$ to $93.8 \%$ ), respectively. Thirty-five of the 66 lesions were located at M1 of the middle cerebral artery, 4 at M2 of the middle cerebral artery, 5 at the basilar artery, 5 at the intracranial vertebral artery (V4 or distal V3) and 17 at the internal carotid artery (including 7 at the terminal segment, 3 at the supraclinoid segment, 3 at the petrous segment, 2 at the cavernous segment, 1 at the ophthalmic segment and 1 at the posterior communicating segment). The average degree of residual stenosis immediately after stenting was 47.2 $\pm 13.2 \%$ (median $46.5 \%, 95 \%$ CI $21.2 \%$ to $73.2 \%$ ). The degrees of stenosis at prestenting baseline and the degree of residual stenosis immediately after stenting of individual cases are shown in figure 1. 
Figure 1 Degree of stenosis at prestenting baseline (indicated by the right end of the white bar) and degree of residual stenosis immediately after stenting (indicated by the right end of the grey bar).
Case number (Not in chronological order)

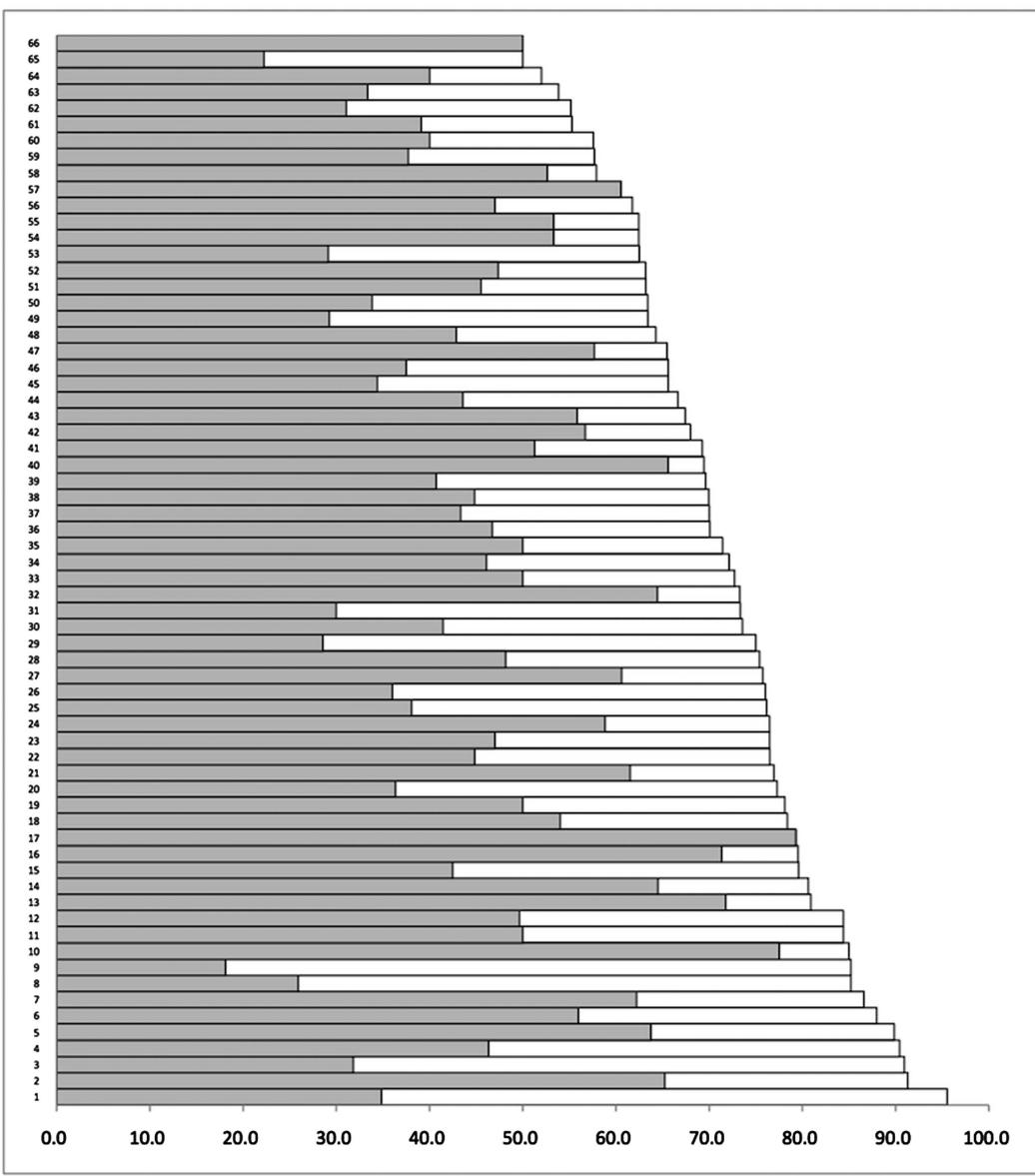

Degree of stenosis (\%)

\section{Study endpoints}

At 1 year there was no recurrence of ipsilateral ischemic stroke or TIA. Compared with the luminal diameter immediately after stenting, DSA at 1 year showed a luminal gain in 32 of the 66 lesions $(48.5 \%)$, an unchanged lumen in $4(6 \%)$ and luminal loss in $30(45.4 \%)$. Luminal loss of $\geq 50 \%$ occurred in 9 of the 66 lesions (13.6\%; table 1). ISR at 1 year, as defined in the WASID trial, ${ }^{12-14}$ occurred in 11 of the 66 lesions $(16.7 \%)$. None of them was symptomatic. By the modified Mehran system there were five Class IA lesions, five Class IB lesions and one Class II lesion. The degree of stenosis of the ISR lesions was more severe than that of the pretreatment lesions in 9 of

\begin{tabular}{|c|c|c|c|c|}
\hline \multirow[b]{2}{*}{ Luminal change } & \multirow[b]{2}{*}{ No $(\%)$ of lesions } & \multicolumn{3}{|c|}{ Degree of luminal change (\%) } \\
\hline & & Average & Median & Range \\
\hline \multicolumn{5}{|l|}{ Luminal loss } \\
\hline$\geq 50 \%$ & $9(13.6)$ & $65.7 \pm 12$ & 67.1 & $50-87.5$ \\
\hline$\geq 20 \%-<50 \%$ & $8(12.1)$ & $28.5 \pm 8.1$ & 25.4 & $20-42.2$ \\
\hline$<20 \%$ & $13(19.7)$ & $12.4 \pm 5.9$ & 13.3 & $2.3-19.6$ \\
\hline Unchanged & $4(6)$ & 0 & 0 & 0 \\
\hline Luminal gain & $32(48.5)$ & $32(48.5 \%)$ & 22.9 & $1-150$ \\
\hline
\end{tabular}

the 11 ISR cases. All 11 ISR lesions were located at a site $\leq 5 \mathrm{~mm}$ from that of the pretreatment lesions.

The periprocedural stroke or death rate within 30 days was $6.1 \%(4 / 65,95 \%$ CI $2 \%$ to $15.8 \%)$. There were three cases of major procedure-related hemorrhage and one major ischemic stroke, all of which occurred at the corresponding territory and resulted in death. One was a subarachnoid hemorrhage in the mid basilar artery which occurred after a second angioplasty for $87 \%$ stenosis. The second hemorrhage was due to dissection of an M1 segment with a micro guidewire during an attempt to recannulate a 90\% stenosis at M1 for stent placement. Angioplasty had been performed at the M1 stenosis and the track was subsequently lost. The third hemorrhage was due to perforation of a perforator at M2 with a micro guidewire during angioplasty. From 30 days to 1 year, no ischemic stroke or hemorrhagic stroke occurred at any sites and there were no deaths from any cause.

Failure to control blood pressure was observed in 26 of the 66 cases of stenosis. Failure to control glycemia, low density lipoprotein and smoking was observed in 19, 34 and 12 cases, respectively. It was found that the degree of stenosis before treatment was correlated with ISR in univariate and multivariate analysis whereas other factors such as patient age, sex, vessel diameter and failure to control risk factors for atherosclerosis were not correlated with ISR (table 2). The incidence of ISR was 10 of 49 cases $(20.4 \%)$ at sites other than the internal carotid artery and 1 of $17(5.9 \%)$ at the internal carotid artery. The incidence of ISR was higher at locations other than the 
Table 2 Analysis of correlations with in-stent restenosis

\begin{tabular}{|c|c|c|}
\hline Factors & $\begin{array}{l}\text { Univariate analysis } \\
\text { ( } p \text { value) }\end{array}$ & $\begin{array}{l}\text { Multivariate analysis* } \\
\text { ( } p \text { value) }\end{array}$ \\
\hline \multicolumn{3}{|l|}{ Patient characteristics } \\
\hline Age $(\geqq 55,<55)$ & $0.501 \dagger$ & 0.186 \\
\hline Sex & $0.711 \dagger$ & 0.481 \\
\hline \multicolumn{3}{|l|}{ Lesion characteristics } \\
\hline Vessel diameter (mm) & $0.235 \ddagger$ & 0.550 \\
\hline Degree of stenosis (\%) & $0.038 \ddagger$ & 0.016 \\
\hline Location (ICA vs non-ICA) & $0.314 \dagger$ & 0.130 \\
\hline \multicolumn{3}{|c|}{ Uncontrolled risk factors for atherosclerosis } \\
\hline Blood pressure & $1 \dagger$ & 0.287 \\
\hline Hyperglycemia & $1 \dagger$ & 0.831 \\
\hline Hypercholesterolemia & $0.406 \dagger$ & 0.459 \\
\hline Smoking & $1+$ & 0.503 \\
\hline $\begin{array}{l}{ }^{*} \text { Mann-Whitney test. } \\
+\chi^{2} \text { test. } \\
\text { fLogistic regression. } \\
\text { ICA, internal carotid artery. }\end{array}$ & & \\
\hline
\end{tabular}

internal carotid artery (OR 4.1) but the difference was not statistically significant $(p=0.314$; table 3 , figures 2 and 3$)$.

\section{DISCUSSION}

This study found no ischemic or hemorrhagic stroke after 30 days and up to 1 year, which is a very promising clinical outcome. The risk of ischemic stroke in the territory of the qualifying artery beyond 30 days and within 1 year following Wingspan stenting reported in the SAMMPRIS trial was $5.8 \%$ $(13 / 224)$; this figure was obtained by deducting 23 patients with the event occurring within 30 days from 36 patients with the event occurring within 1 year. $^{7}$ Although we cannot compare

Table 3 Analysis of vessel and stenosis characteristics and rate of in-stent restenosis by location of lesion

\begin{tabular}{|c|c|c|c|}
\hline & $\begin{array}{l}\text { All other sites } \\
\text { ( } 49 \text { lesions of } \\
\text { stenosis) }\end{array}$ & $\begin{array}{l}\text { Internal carotid } \\
\text { artery ( } 17 \\
\text { lesions } \\
\text { of stenosis) }\end{array}$ & p Value \\
\hline \multicolumn{4}{|c|}{ Diameter of artery } \\
\hline Mean \pm SD & $2.8 \pm 0.5$ & $3.4 \pm 0.6$ & $<0.001$ (Mann-Whitney) \\
\hline $95 \% \mathrm{Cl}$ & 1.7 to 3.9 & 2.3 to 4.6 & \\
\hline Median & 2.7 & 3.3 & \\
\hline IQR & $2.5-3.1$ & $2.9-3.9$ & \\
\hline \multicolumn{4}{|c|}{ Degree of stenosis before stenting } \\
\hline Mean \pm SD & $73.2 \pm 11.4$ & $67.6 \pm 10.0$ & 0.127 (Mann-Whitney) \\
\hline $95 \% \mathrm{Cl}$ & 51.0 to 95.5 & 48.0 to 87.1 & \\
\hline Median & 75.0 & 69.9 & \\
\hline IQR & $63.3-82.6$ & $62.9-75.0$ & \\
\hline \multicolumn{4}{|c|}{ Degree of stenosis post-stenting } \\
\hline Mean \pm SD & $47.7 \pm 13.9$ & $45.7 \pm 11.2$ & 0.538 (Mann-Whitney) \\
\hline $95 \% \mathrm{Cl}$ & 20.4 to 75.1 & 23.7 to 67.7 & \\
\hline Median & 47.0 & 44.8 & \\
\hline IQR & $37.0-58.2$ & $38.3-52.3$ & \\
\hline \multicolumn{4}{|c|}{ In-stent restenosis } \\
\hline Incidence & $10(20.4 \%)$ & $1(5.9 \%)$ & $0.314\left(\chi^{2}\right)$ \\
\hline $95 \% \mathrm{Cl}$ & $10.7 \%$ to $34.8 \%$ & $0.3 \%$ to $30.8 \%$ & \\
\hline Odds & 0.2564 & 0.0625 & $\mathrm{OR}=4.1$ \\
\hline
\end{tabular}

the findings directly between the two studies, it is possible that the risk of recurrent stroke following Wingspan stenting is lower among Asians than among Caucasians. If this is the case, it may indicate that the value of angioplasty and stenting using the Wingspan and Gateway system for prevention of recurrent stroke is higher for Asians than for Caucasians.

In the assessment of ISR using an established methodology, 89 the ISR rate at 1 year in our study was reasonably promising and relatively low compared with that reported in other published studies. Our results also suggest that age is probably unrelated to ISR and that lesions located in the internal carotid artery are probably less prone to ISR. These findings are different from those reported in other studies. ${ }^{8} 9$

A multicenter study on Wingspan stenting from the USA showed that the overall incidence of ISR was 32.3\% (41/127), including 28.3\% (36/127) ISR and 3.9\% (5/127) complete stent occlusion; $36.6 \%(15 / 41)$ cases of ISR were symptomatic. ${ }^{8}$ In that study, the mean imaging follow-up time was 8.5 months rather than 12 months (range $3-15.5$ ). ${ }^{8}$ In a single-center study in the USA the ISR rate was $24 \%(7 / 29)$ on DSA at a mean of 8.6 months (range $3-20$ ). ${ }^{10}$ In another paper based on the same American multicenter study, the ISR was noted to be associated with younger age $(45.2 \%(14 / 31)$ at $\leq 55$ years of age vs $23.2 \%$ $(15 / 62)$ at $>55$ years) and with location of the lesion in the internal carotid artery $(43.7 \%(14 / 32)$ vs $24.6 \%(15 / 61)$ at other locations). ${ }^{9}$ In that study, the mean imaging follow-up time was 7.3 months (range 2-18).

In the current study of post-stenting restenosis, in addition to the standard methodology of assessing stenosis ${ }^{12-14}$ we also assessed the degree of luminal gain or loss compared with the luminal diameter immediately after stenting. Using this method, we have additional information on the degree of luminal gain or loss at 1 year, which represents the actual luminal change compared with the lumen immediately after stenting, independent of the degree of residual stenosis immediately after stenting. We found that further luminal gain compared with the post-stenting baseline occurred in almost half the cases $(32 / 66,48.5 \%)$ during the 1 -year period following stenting (table 1 ).

A major difference between the current study and previous studies is that this is a single-center rather than a multicenter study and procedures in the study were performed by a team of only two operators using a homogeneous technique, free from the influence of variability of techniques among different centers. In a single center the opportunity to accumulate experience during the learning curve period probably also allows greater consistency in the performance of the procedures. Another difference was that the current study involved Asian patients whereas the previous studies have involved Caucasian patients. In addition, there were a number of differences between our treatment protocol and those in previous studies. First, we performed the procedures only under local anesthesia without patient sedation due to the relative shortage of resources for general anesthesia in our center. Performing the procedure without general anesthesia or sedation meant that patients remained fully conscious and allowed doctors to stop the procedure early on detection of ischemic symptoms or severe headache during the procedure. We did not come across technical problems in the procedure or procedural complications because of the lack of general anesthesia. Four procedures were abandoned because of ischemic symptoms or severe headache, and we believe that ischemic infarction or damage to blood vessels could be prevented because of this. Second, we used a modest dose of intraprocedural heparin to minimize the risk of periprocedural intracranial hemorrhage, especially that 

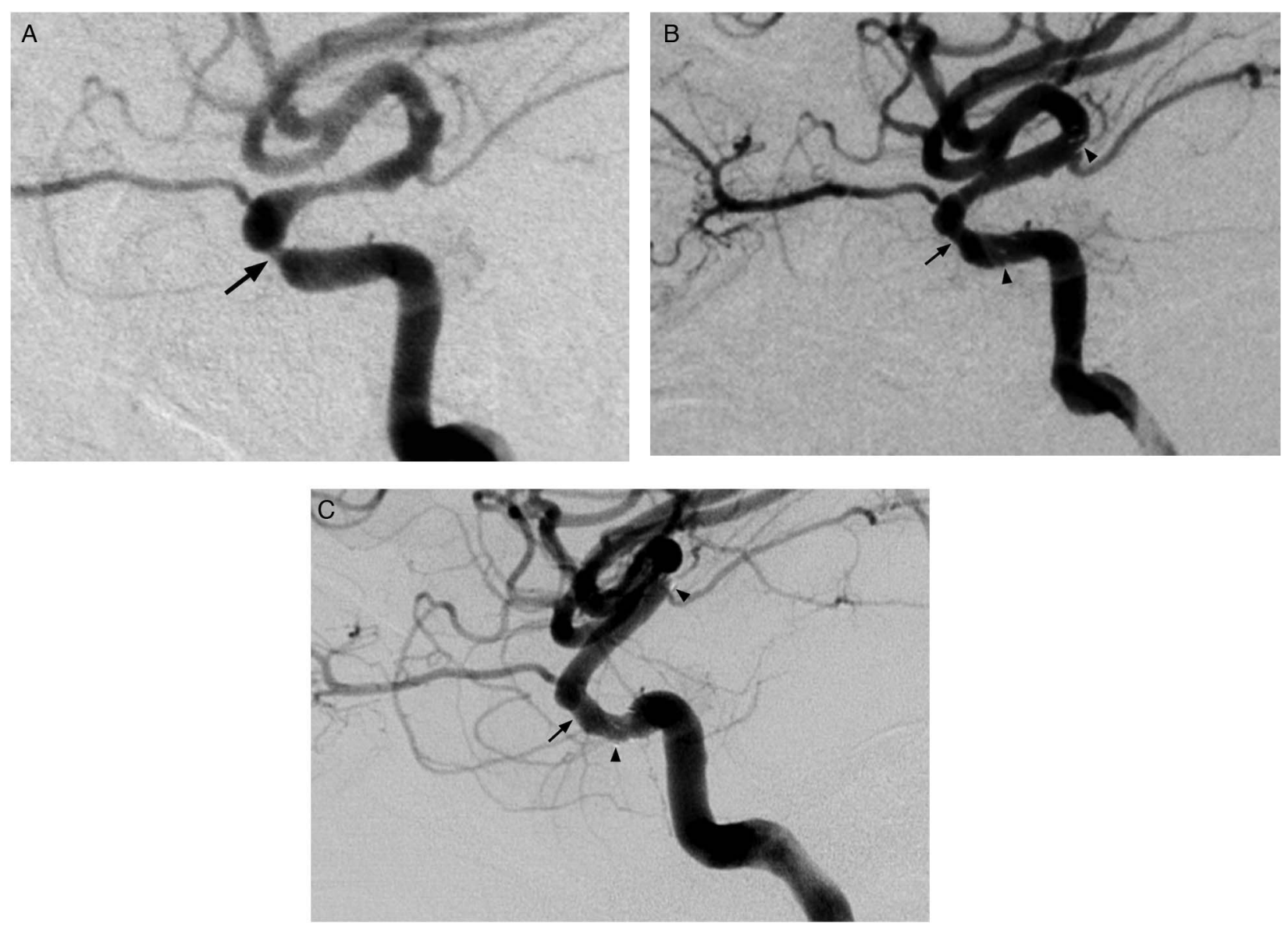

Figure 2 In a man with stenosis at the carotid siphon, digital subtraction angiography showed $62.5 \%$ stenosis at prestenting baseline (A), a residual stenosis of $53.3 \%$ immediately post-stenting (B), and $18.2 \%$ stenosis at 1 year (C). There was a $75 \%$ luminal gain 1 year after stenting (C). The lesion is shown by an arrow and the ends of the stent are indicated by arrowheads.

due to hyperperfusion. Third, because our patients were fully conscious, we used a short inflation time of $<10 \mathrm{~s}$ in the angioplasty procedure instead of the standard inflation time of $120 s^{4-68} 9$ to reduce the risk of ischemic symptoms which might affect patient cooperation. Although a short inflation time may potentially lead to a higher risk of arterial dissection or embolism during angioplasty, these events did not occur in any of the post-angioplasty DSA so we believe it is safe. Fourth, prestenting assessment with 3DRA in addition to DSA was used routinely to ensure exclusion of vascular fenestration from the procedure of angioplasty and stenting and to allow thorough assessment of the morphology of the stenotic lesion.

The exact reason for a lower rate of ISR in our study compared with the multicenter study remains to be elucidated. ${ }^{8} 912$ The reason for a lower incidence of ISR in lesions located in the internal carotid artery-the opposite finding to that observed in the multicenter study-is also unknown. We do not know the effect of our practice of using a short inflation time of angioplasty on the ISR rate. Further studies on the effect of inflation time on ISR are required to address the above observations, including histological studies in animal models on the effect of mucosal necrosis, granulation formation and fibrosis.

Failure to control risk factors for atherosclerosis is a known etiological factor for intracranial stenoses, but it was not correlated with ISR at 1 year in our study. This finding suggests that a longer time period may be required for the risk factors of atherosclerosis to exert their effect on the manifestation of ISR and, in the meantime, local factors such as the atherosclerotic plaque itself, the effect of angioplasty and the mechanical presence of the stent may be more important for the occurrence of ISR.

Periprocedural complications in the SAMMPRIS trial were mainly due to ischemic stroke $(63.3 \%, 19 / 30)$, which was largely due to perforator stroke $(63.1 \%, 12 / 19)$ and others such as embolic, mixed perforator and embolic, and stent occlusion. The other periprocedural complications were due to hemorrhagic stroke, either subarachnoid $(45.5 \%, 5 / 11)$ or intracerebral $(54.5 \%, 6 / 11) .^{23}$ Five of the six intracerebral hemorrhages $(83.3 \%)$ presented $\geq 4 \mathrm{~h}$ after stenting. All cases of fatal hemorrhage were due to intracerebral hemorrhage. The pattern of causes of periprocedural complications in our study was different from that seen in the SAMMPRIS trial. In our study periprocedural hemorrhagic complications were largely due to guidewire or angioplasty-related complications (75\%, 3/4); delayed intracerebral hemorrhage presenting $\geq 4 \mathrm{~h}$ after the procedure did not occur. Perforator stroke did not occur in any of our 36 cases of stenosis at the middle cerebral artery and the 5 cases of stenosis at the basilar artery. In fact, we found in our previous study that stenting with the Wingspan system in the middle cerebral arteries did not pose an increased risk of new perforator infarcts on MRI. ${ }^{24}$ The reason for the lack of periprocedural perforator stroke in our study is not known, but it is not unreasonable to speculate that the short inflation time during angioplasty could be a contributory factor. Our practice of using a moderate intraprocedural dose of intravenous heparin (2500 IU) to maintain an activated clotting time of $180-250 \mathrm{~s}$ 

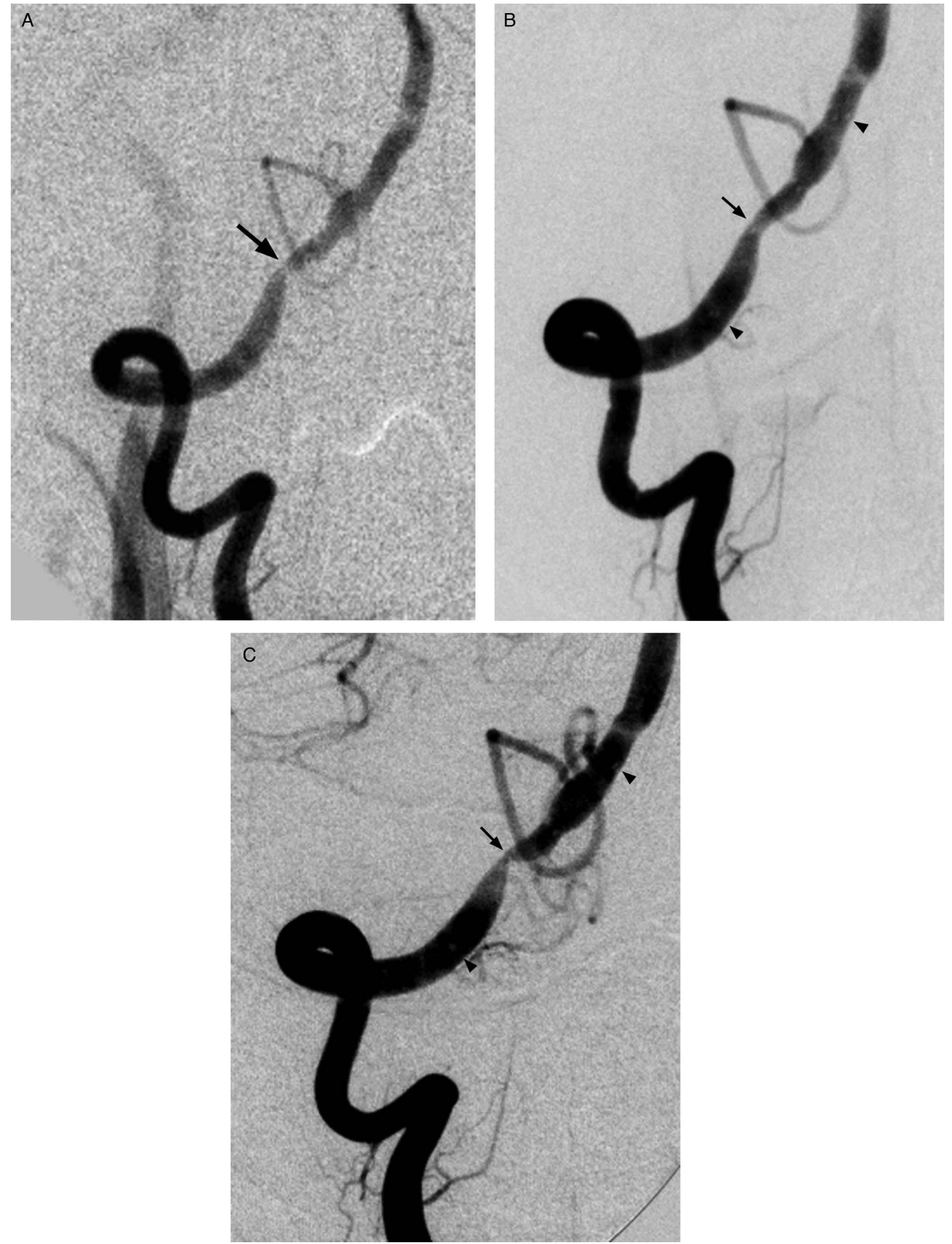

Figure 3 In a man with stenosis at distal V3, digital subtraction angiography showed $66.7 \%$ stenosis at prestenting baseline (A), a residual stenosis of $43.6 \%$ immediately post-stenting (B), and $86.6 \%$ stenosis at 1 year (C). There was a $72.7 \%$ luminal loss 1 year after stenting (C). The lesion is shown by an arrow and the ends of the stent are indicated by arrowheads.

and avoiding the use of multiple loading doses of preprocedural clopidogrel may help to reduce the risk of periprocedural intracerebral hemorrhage.

One limitation of the current study is that the number of lesions being assessed was relatively small. Furthermore, the scope and design of our study did not allow us to explain the differences between the findings of our study and those of the multicenter study. The absence of independent verification of events during the follow-up period is also a significant limitation. 
In conclusion, the 1-year clinical and angiographic outcome of angioplasty and stenting using the Wingspan and Gateway system for intracranial atherosclerosis in Asian patients is reasonably promising with a low recurrent stroke rate and a low rate of ISR.

Acknowledgements The authors thank Mr Clinton Wong for his technical support in the treatment procedures and Miss Tiffany Lau for data management and analysis.

Contributors All authors made substantial contributions to the conception and design of the study; acquisition of data or analysis and interpretation of the data; drafting the article or revising it critically for important intellectual content; and final approval of the manuscript.

Funding This study was partly supported by the Vascular and Interventional Radiology Foundation, which is a charitable organization. It was not sponsored by any other grant or funding from any commercial company.

Competing interests None.

Ethics approval Ethics approval was obtained from the Clinical Research Ethics Committee of The Chinese University of Hong Kong.

Provenance and peer review Not commissioned; externally peer reviewed.

Open Access This is an Open Access article distributed in accordance with the Creative Commons Attribution Non Commercial (CC BY-NC 3.0) license, which permits others to distribute, remix, adapt, build upon this work non-commercially, and license their derivative works on different terms, provided the original work is properly cited and the use is non-commercial. See: http://creativecommons.org/ licenses/by-nc/3.0

\section{REFERENCES}

1 Sacco RL, Kargman DE, Gu Q, et al. Race-ethnicity and determinants of intracrania atherosclerotic cerebral infarction. The Northern Manhattan Stroke Study. Stroke 1995;26:14-20.

2 Broderick J, Brott T, Kothari R, et al. The Greater Cincinnati/Northern Kentucky Stroke Study: preliminary first-ever and total incidence rates of stroke among blacks. Stroke 1998;29:415-21.

3 Wong KS, Huang YN, Gao S, et al. Intracranial stenosis in Chinese patients with acute stroke. Neurology 1998;50:812-13.

4 Bose $\mathrm{A}$, Hartmann $\mathrm{M}$, Henkes $\mathrm{H}$, et al. A novel, self-expanding, nitinol stent in medically refractory intracranial atherosclerotic stenoses: the Wingspan study. Stroke 2007;38:1531-7

5 Fiorella D, Levy El, Turk AS, et al. US multicenter experience with the wingspan stent system for the treatment of intracranial atheromatous disease: periprocedural results. Stroke 2007;38:881-7.

6 Zaidat 00, Klucznik R, Alexander MJ, et al. NIH Multi-center Wingspan Intracranial Stent Registry Study Group. The NIH registry on use of the Wingspan stent for symptomatic 70-99\% intracranial arterial stenosis. Neurology 2008;70:1518-24.

7 Chimowitz MI, Lynn MJ, Derdeyn CP, et al. Stenting versus aggressive medical therapy for intracranial arterial stenosis. N Engl J Med 2011;365:993-1003.

8 Albuquerque FC, Levy El, Turk AS, et al. Angiographic patterns of Wingspan in-stent restenosis. Neurosurgery 2008;63:23-7, discussion 27-8.
9 Turk AS, Levy El, Albuquerque FC, et al. Influence of patient age and stenosis location on wingspan in-stent restenosis. AJNR Am J Neuroradiol 2008;29:23-7.

10 Wolfe BF, Hussain SI, Lynch JR, et al. Long term clinical and angiographic outcomes with the wingspan stent for treatment of symptomatic $50-99 \%$ intracranial atherosclerosis: single center experience in 51 cases. J Neurointerv Surg 2009;1:40-3.

11 Nahab F, Lynn MJ, Kasner SE, et al. Risk factors associated with major cerebrovascular complications after intracranial stenting. Neurology 2009:72:2014-19.

12 Levy El, Turk AS, Albuquerque FC, et al. Wingspan in-stent restenosis and thrombosis: incidence, clinical presentation, and management. Neurosurgery 2007:61:644-50, discussion 650-1.

13 Chimowitz MI, Lynn MJ, Howlett-Smith $\mathrm{H}$, et al. Comparison of warfarin and aspirin for symptomatic intracranial arterial stenosis. N Engl J Med 2005;352:1305-16

14 Samuels OB, Joseph GJ, Lynn MJ, et al. A standardized method for measuring intracranial arterial stenosis. Am J Neuroradiol 2000;21:643-6.

15 Mehran R, Dangas G, Abizaid AS, et al. Angiographic patterns of in-stent restenosis: classification and implications for long-term outcome. Circulation 1999;100:1872-8.

16 Chobanian AV, Bakris GL, Black HR, et al. National Heart, Lung, and Blood Institute Joint National Committee on Prevention, Detection, Evaluation, and Treatment of High Blood Pressure; National High Blood Pressure Education Program Coordinating Committee. The Seventh Report of the Joint National Committee on Prevention, Detection, Evaluation, and Treatment of High Blood Pressure: the JNC 7 report. JAMA 2003;289:2560-72.

17 PROGRESS Collaborative Group. Randomised trial of a perindopril-based blood-pressure-lowering regimen among 6105 individuals with previous stroke or transient ischaemic attack. Lancet 2001;358:1033-41.

18 Skyler JS, Bergenstal R, Bonow RO, et al. Intensive glycemic control and the prevention of cardiovascular events: implications of the ACCORD, ADVANCE, and VA Diabetes Trials: a position statement of the American Diabetes Association and a Scientific Statement of the American College of Cardiology Foundation and the American Heart Association. J Am Coll Cardiol 2009:53:298-304.

19 Heart Protection Study Collaborative Group. Effects of cholesterol-lowering with simvastatin on stroke and other major vascular events in 20,536 people with cerebrovascular disease or other high risk conditions. Lancet 2004;363:757-7.

20 Amarenco P, Bogousslavsky J, Callahan A III, et al. Stroke Prevention by Aggressive Reduction in Cholesterol Levels (SPARCL) Investigators. High-dose atorvastatin after stroke or transient ischemic attack. N Engl J Med 2006;355:549-9.

21 Ridker PM, Danielson E, Fonseca FA. Rosuvastatin to prevent vascular events in men and women with elevated C-Reactive protein. JUPITER Study Group. N Engl J Med 2008:359:2195-207.

22 Expert Panel on Detection, Evaluation, and Treatment of High Blood Cholesterol in Adults. Executive summary of the third report of the national cholesterol education program (NCEP) expert panel on detection, evaluation, and treatment of high blood cholesterol in adults (adult treatment panel III). JAMA 2001;285:2486-97.

23 Fiorella D, Derdeyn CP, Lynn MJ, et al. Detailed analysis of periprocedural strokes in patients undergoing intracranial Stenting in Stenting and Aggressive Medical Management for Preventing Recurrent Stroke in Intracranial Stenosis (SAMMPRIS). Stroke 2012;43:2682-8

24 Leung TW, Yu SCH, Lam WWM, et al. Would self-expanding stent occlude middle cerebral artery perforators? Stroke 2009;40:1910-12. 